\title{
Cyclooxygenase inhibitors decrease the growth and induce regression of human esophageal adenocarcinoma xenografts in nude mice
}

\author{
SONIA SANTANDER ${ }^{1,2}$, CARMELO CEBRIÁN $^{3}$, PAULA ESQUIVIAS $^{4}$, BLANCA CONDE $^{2}$, \\ FRANCISCO ESTEVA $^{2,5}$, PILAR JIMÉNEZ ${ }^{4}$, JAVIER ORTEGO ${ }^{2,3}$, ÁNGEL LANAS ${ }^{1,2,4,6}$ and ELENA PIAZUELO ${ }^{1,2,4}$ \\ ${ }^{1}$ IIS Aragón, ${ }^{2}$ University of Zaragoza, ${ }^{3}$ Service of Pathology, ${ }^{4}$ Networked Biomedical Research Center of Hepatic and Digestive \\ Diseases (CIBERehd), ${ }^{5}$ Service of Clinical Biochemistry, ${ }^{6}$ Service of Gastroenterology, University Hospital, Zaragoza, Spain
}

Received July 29, 2011; Accepted September 14, 2011

DOI: 10.3892/ijo.2011.1219

\begin{abstract}
Cyclooxygenase (COX) inhibition has been shown to prevent the development of esophageal adenocarcinoma (EAC). However, the potential of this approach for treatment of established cancer has been poorly investigated. Our objective was to determine whether non-selective or selective inhibition of the COX pathway affects the growth of esophageal adenocarcinoma xenografts in nude mice. A human esophageal adenocarcinoma xenograft model was established by subcutaneous inoculation of OE33 cells in nude mice. Small tumor slices harvested from four OE33 xenografts were implanted in the flanks of new mice that were randomized to different treatments (6 animals per group): indomethacin $(3 \mathrm{mg} / \mathrm{kg} / \mathrm{day})$, parecoxib $(0.11$ and $0.22 \mathrm{mg} /$ $\mathrm{kg} /$ day) or a selective prostaglandin $\mathrm{E}_{2}$ receptor antagonist (AH-23848B, $1 \mathrm{mg} / \mathrm{kg} / \mathrm{day})$. For each treatment, a control group of 6 animals (vehicle) carrying xenografts from the same OE33 tumor was included. Tumor growth was measured twice a week. After 8 weeks mice were euthanized. Tumors were assessed by histological analysis, mRNA expression of COX isoenzymes, $\mathrm{PGE}_{2}$ receptors and $\mathrm{PGE}_{2}$ content. All OE33 tumors were poorly differentiated esophageal adenocarcinomas. Tumors expressed $\mathrm{COX}-2, \mathrm{EP}_{1}, \mathrm{EP}_{2}$ and $\mathrm{EP}_{4}$ receptor mRNA. Treatment with parecoxib, higher dose or indomethacin significantly inhibited tumor growth. Furthermore, indomethacin induced tumor regression (74 vs $582 \%$ in control animals; $\mathrm{p}<0.01$ ). However, AH-23848B or parecoxib low dose failed to affect tumor growth significantly. $\mathrm{PGE}_{2}$ content in tumors was significantly decreased by high-dose parecoxib and indomethacin. Indomethacin and parecoxib inhibit the growth of human esophageal adenocarcinoma xenografts in nude mice, which suggests a potential role for NSAIDs or selective COX-2 inhibitors for EAC chemotherapy.
\end{abstract}

Correspondence to: Dr Sonia Santander Ballestín, Aragon Health Research Institute (IIS Aragon), University of Zaragoza School of Medicine, Department of Pharmacology and Physiology, C/Domingo Miral s/n, 50009 Zaragoza, Spain

E-mail: soniasb@gmail.com

Key words: esophageal adenocarcinoma, xenograft, nude mice, cyclooxygenase, EP receptors

\section{Introduction}

In the last decades, the incidence of esophageal adenocarcinoma in the United States and Western Europe has risen at a more rapid rate than that of any other cancer, becoming now the most frequent type of esophageal cancer in these countries $(1,2)$. This tumor has a very poor prognosis. Once diagnosed, 5-year survival is $<15 \%$ despite surgery and neo-adjuvant chemotherapy regimes, which contributes to make esophageal carcinoma the 6th most deadly cancer throughout the world (3). For this reason, current research focuses on looking for targets for developing new chemotherapeutic strategies. One of these potential targets is cyclooxygenase-2. Indeed, the role of COX-2 in carcinogenesis and cancer progression has been reported in many cancers, including esophageal adenocarcinoma. Evidence supporting the involvement of COX-2 in esophageal adenocarcinoma includes epidemiological studies which have demonstrated a protective effect of NSAIDs against esophageal adenocarcinoma $(4,5)$, in vivo studies in experimental models of reflux-induced esophageal adenocarcinoma in rats, where administration of non-steroidal anti-inflammatory drugs (NSAIDs) or selective COX-2 inhibitors (coxibs) induced a reduction of esophageal cancer incidence (6-10). In addition, up-regulation of COX-2 has been described both at mRNA and protein level along the Barrett's metaplasia-dysplasia-adenocarcinoma sequence in humans (11-17) and COX-2 expression has been identified as an independent prognostic variable for esophageal adenocarcinoma (18), indicating that COX-2 could be a molecular target for specific chemotherapeutic treatment.

Of the five major prostanoids that are derived from the action of COX-2, prostaglandin $\mathrm{E}_{2}\left(\mathrm{PGE}_{2}\right)$ is considered the most important downstream effector in carcinogenesis since it stimulates proliferation, inhibits apoptosis, favours motility, invasion and promotes angiogenesis. $\mathrm{PGE}_{2}$ exerts its actions through the activation of $\mathrm{G}$ protein coupled receptors, known as the EP receptors. There are four subtypes of EP receptors designated as $\mathrm{EP}_{1}, \mathrm{EP}_{2}, \mathrm{EP}_{3}$, and $\mathrm{EP}_{4}(19,20)$. Classically the $\mathrm{EP}_{1}$ and $\mathrm{EP}_{3}$ receptors couple to $\mathrm{G} \alpha \mathrm{q}$ and $\mathrm{G} \alpha \mathrm{i}$ to activate $\mathrm{Ca}^{2+}$ signalling and inhibition of adenylyl cyclase, respectively. The $\mathrm{EP}_{2}$ and $\mathrm{EP}_{4}$ receptors couple to Gas to stimulate adenylyl cyclase and activate cAMP/protein kinase A (PKA) signaling (21-25). 
More recently $\mathrm{EP}_{4}$ receptors have been shown to couple to $\mathrm{G \alpha i}$ and activate phosphoinositide 3-kinase (PI3K) signaling (26). In recent years, EP receptors have been proposed as potential more selective targets downstream COX since several studies have demonstrated that the blockage of several of these receptors using genetic delection or pharmacologic manipulation is as effective as COX inhibition in the prevention of colorectal cancer in mice (27-29). The majority of studies indicate that $\mathrm{EP}_{1}, \mathrm{EP}_{2}$, or $\mathrm{EP}_{4}$ promote early carcinogenesis, whereas $\mathrm{EP}_{3}$ either does not contribute to tumor behavior or actually plays a protective role. In a previous study, we reported that $\mathrm{EP}_{1}, \mathrm{EP}_{2}$ or $\mathrm{EP}_{4}$ receptors mediates the effects of $\mathrm{PGE}_{2}$ on proliferation, apoptosis and migration of espophageal adenocarcinoma cells (30).

So far, most studies with NSAIDs and selective COX-2 inhibitors have focused on their effect in the chemoprevention of dysplasia or esophageal adenocarcinoma in Barrett's esophagus patients, but the potential of COX inhibition for treatment of esophageal adenocarcinoma once established, has been scarcely explored (31). On the other hand, the potential of EP receptors as therapeutic targets downstream COX-2 in esophageal adenocarcinoma has not been studied either. Therefore, the aim of the present study was to assess the impact of the inhibition of COX pathway at several levels in an animal model of established esophageal adenocarcinoma. For this purpose, we investigated whether a non-selective COX1/ COX2 inhibitor (indomethacin), a selective COX-2 inhibitor (parecoxib) or a selective $\mathrm{EP}_{4}$ antangonist (AH23848B), inhibit tumor growth of human esophageal adenocarcinoma xenografts in nude mice.

\section{Materials and methods}

Reagents. Parecoxib (sodium parecoxib, Dynastat) was kindly provided by Pfizer (Madrid, Spain). AH-23848B (an $\mathrm{EP}_{4}$ antagonist) was a gift from GlaxoSmithKline (Stevenage, UK). Indomethacin was purchased from Sigma-Aldrich (St. Louis, $\mathrm{MO})$. Ethanol was used as the solvent for parecoxib and indomethacin and DMSO for AH-23848B stock that was daily diluted in ethanol at the desired concentration.

Drugs selection, dosage and administration route. We tested two different cyclooxygenase inhibitors, a classic NSAID, indomethacin, and a selective COX-2 inhibitor, parecoxib. This COX-2 inhibitor was selected, because, in contrast to other commercially available selective COX-2 inhibitors, is watersoluble. Among the different $\mathrm{PGE}_{2}$ receptors, we chose to use an $\mathrm{EP}_{4}$ antagonist since this receptor was the one which showed the highest expression in OE33 tumors. All drugs were administered in drinking water. We chose this administration route because we considered it to be the less stressful way to administer the drugs in a daily basis during 8 weeks. The concentration of drugs in water was calculated using an average weight of $25 \mathrm{~g}$ and a daily consumption of $10 \mathrm{ml}$ water per day. This amount of water consumption had been evaluated in previous experiments. Indomethacin was given at $3 \mathrm{mg} / \mathrm{kg} /$ day since this dose had been previously shown to suppress the growth of gastric cancer xenografts in nude mice (32). Parecoxib was given at low doses of $0.11 \mathrm{mg} / \mathrm{kg}$ and twice that dose, $0.22 \mathrm{mg} / \mathrm{kg}$, to avoid any adverse effect. Regarding AH-23848, since there were not any studies evaluating its effect in cancer, we based on a previous study which reported oral administration of AH-23848 in animals and men showing biological effect without causing adverse effects (33). Due to limitation of this non-commercially available drug, only this dose was tested. The drug was replaced on a daily basis and administered in dark bottles in order to avoid light degradation.

Cell line. OE33 cells were purchased from the American Type Tissue Collection. This cell line was established from the adenocarcinoma of the lower esophagus (Barrett's metaplasia) of a 73-year old female patient. The tumor was identified as pathological stage IIA (UICC) and showed poor differentiation. The cells express epithelial cytokeratins and have been described as tumorigenic in nude mice (34). These OE33 cells were grown on plastic culture dishes according to standard cell culture techniques and maintained as monolayer cultures in RPMI-1640 medium supplemented with $10 \%$ fetal calf serum (FBS) and L-glutamine. For animal experiments, cells were harvested and manually counted using a Neubauer Chamber.

Animals. All procedures were approved by the in-house Ethics Committee for Animal Experiments from the University of Zaragoza. The care and use of animals were performed accordingly with the Spanish Policy for Animal Protection RD1201/05, which meets the European Union Directive 86/609 on the protection of animals used for experimental and other scientific purposes 5-6-week old male nude mice (Swiss nu/nu), weighing ( $25 \mathrm{~g}$ ) were purchased from Charles River (Barcelona, Spain). The nude mice were caged individually under specificpathogen free (SPF) conditions and were maintained under controlled conditions of temperature $\left(23 \pm 3^{\circ} \mathrm{C}\right)$ and relative humidity $(50 \pm 20 \%)$ in the animal facility of the University of Zaragoza for animal experimentation in a specific pathogen-free environment. The animals were allowed free access to sterilized food and autoclaved water throughout the acclimatization and experimental periods.

Animal model and experimental designs. OE33 cells in the logarithmic phase of growth were harvested with trypsin-EDTA and resuspended in sterile media, then pelleted by brief centrifugation at $1500 \mathrm{rpm}\left(5 \mathrm{~min}\right.$ at $\left.4^{\circ} \mathrm{C}\right)$. The supernatant was aspirated, and cells were re-suspended in serum-free medium to yield a final concentration of $10^{8}$ cells $/ \mathrm{ml}$. Cell suspension $(100 \mu \mathrm{l})$ (total of $10^{7}$ cells injected) was injected subcutaneously using a tuberculin syringe and a 27 -gauge needle in the back of nude mice $(n=4)$ to establish a model of tumor-bearing mice. Once tumor grew, fragments of the tumor were passed to others mice until experiments were developed. Four mice bearing OE33 tumors were used for this study. OE33 tumors were extracted during the exponential growth phase (4 weeks). Necrotic tissue was removed and the remaining fresh tumor tissues were cut into small pieces of $\sim 0.1-0.2 \mathrm{~cm}^{3}$ size. The OE33 xenograft model was established by implanting subcutaneously these tumor pieces in the back of new mice immediately after extracted (Fig. 1). For this procedure, the mice were anaesthetized with i.p. injection of ketamine and xylazine (100 and $10 \mathrm{mg} / \mathrm{kg}$ body weight, respectively) and allowed to stabilize under anaesthesia for $15 \mathrm{~min}$. An incision of $6 \mathrm{~mm}$ was made through the skin in the area of the left lateral subcostal and a fragment of OE33 tumor was filled 

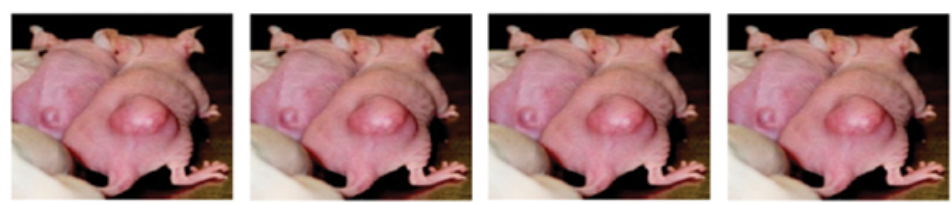

Tumor extraction and
fragmentation (AP)

Reinoculation of

fragments into new

mice $(n=12)$

7 DAYS

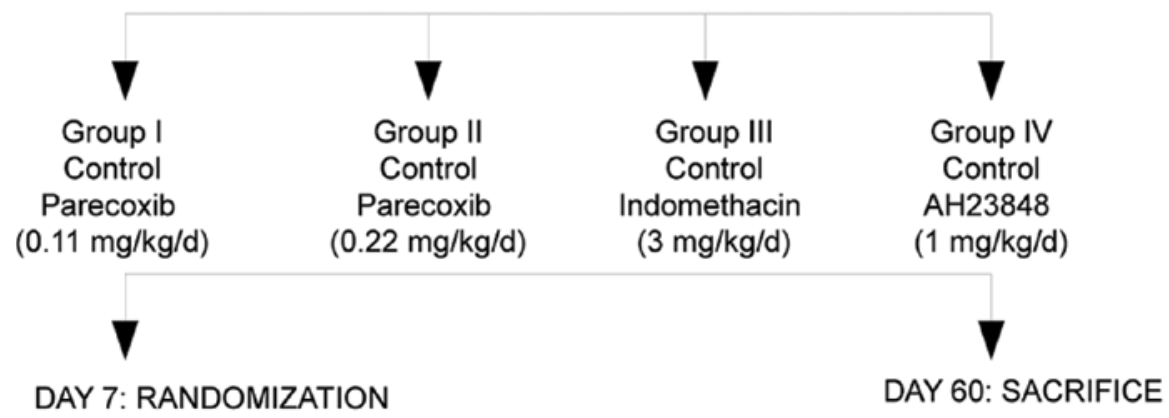

Figure 1. Experimental design. Four different mice bearing an OE33 xenograft were used for this study. Tumor was extracted and fragmented into slices of $0.1-0.2 \mathrm{~cm}^{3}$ that were immediately implanted subcutaneously into new mice (twelve animals per OE33 xenograft). After 7 days, when wounds were healed, the twelve mice of each experiment were aleatory randomized to control or treatment group. At day 0 , mice were then randomly divided into groups of 6 animals each: control group vs. treatment group. A total of four treatments were evaluated in four different experiments: indomethacin $3 \mathrm{mg} / \mathrm{kg} / \mathrm{day}, \mathrm{parecoxib} 0.11 \mathrm{mg} / \mathrm{kg} / \mathrm{day}, \mathrm{parecoxib} 0.22 \mathrm{mg} / \mathrm{g} /$ day and AH-23848B $1 \mathrm{mg} / \mathrm{kg} /$ day. Tumor sizes were measured three times weekly and tumor volume was determined by external measurement, according to the equation $\mathrm{V}=\left[\mathrm{LxW}^{2}\right] \times 0.5$, where $\mathrm{V}$ is volume, $\mathrm{L}$ is length, and $\mathrm{W}$ is width.

under mouse skin with steril forceps. The margins of the wound were approximated and closed with an adhesive plaster. Seven days post-operatively, once the wound was healed, animals were randomly divided into two groups: the control group $(n=6)$, which received vehicle and the treatment group $(n=6)$. A total of four treatments were evaluated in four different experiments: indomethacin $3 \mathrm{mg} / \mathrm{kg} / \mathrm{day}$, parecoxib $0.11 \mathrm{mg} / \mathrm{kg} /$ day, parecoxib $0.22 \mathrm{mg} / \mathrm{kg} / \mathrm{day}$ and AH-23848 $1 \mathrm{mg} / \mathrm{kg} /$ day. One OE33 tumor was used for each experiment, in such a way that both control animals and those receiving treatment bear xenografts from the same tumor. After 8 weeks, mice were sacrificed by a intaperitoneal injection of dolethal. Immediately, tumors were excised and a representative half portion was fixed in $10 \%$ buffered formalin for $24 \mathrm{~h}$ and paraffin-embebed. Sections $(5 \mu \mathrm{m})$ were cut and stained with H\&E for histopathological analysis. The rest of the tumor was divided into two fragments, which were snap-frozen and stored at $-80^{\circ} \mathrm{C}$ for measurement of the mRNA expression and $\mathrm{PGE}_{2}$ levels.

Tumor measurements and general observation of mice. General conditions of the mice were observed every day. The size of the tumor was determined by direct measurement of tumor dimensions (the shortest and the longest diameter) with a caliper at 2-day intervals. Tumor volume $\left(\mathrm{mm}^{3}\right)$ was calculated using the standard formula: $\mathrm{V}=\mathrm{W}^{2} \mathrm{xLx} 0.5$, where $\mathrm{W}$ is the shortest diameter and $\mathrm{L}$ is the longest diameter. Relative tumor volumes (Vt) were calculated for each individual tumor according to tumor size on day 60 divided by tumor size on day 0 , i.e., at randomization, multiplied by 100 . Group median relative tumor volumes were used for evaluation. The day of randomization was designated as day 0 . Day 0 was also the first day of dosing. The experiments were evaluated after 2 months for growing tumors. Tumor growth inhibition (TI) was used to assess the antitumor effects against xenografts. The drug was considered to be active when the tumor growth inhibition obtained in a given xenograft model was $\geq 50 \%$, very active when $\geq 75 \%$ and inactive when $\leq 50 \%$. The formula for TI $(\%)$ is $(1-\mathrm{Vt} / \mathrm{Vc}) \times 100 \%$, where $\mathrm{Vt}$ is the mean tumor volume of the treated group and $\mathrm{Vc}$ is the mean tumor volume of the control group. Complete tumor remission (Rt) was defined as the disappearance of a tumor for at least 1 month after treatment. The formula for $\mathrm{Rt}$ is $(\mathrm{Vt} / \mathrm{Vi}) \mathrm{x} 100$, where $\mathrm{Vi}$ is the tumor volume at day 0 . Tumor remission is considered when $\mathrm{Rt}=50 \%$; $\mathrm{Rt}=51-75 \%$ : minimum regression; $\mathrm{Rt}=76-125 \%$ : no variation; $\mathrm{Rt}>125 \%$ : tumor progression $(35,36)$.

Real-time polymerase chain reaction. Subcutaneous OE33 tumor tissues were subject to total RNA extraction using a Mini RNeasy 


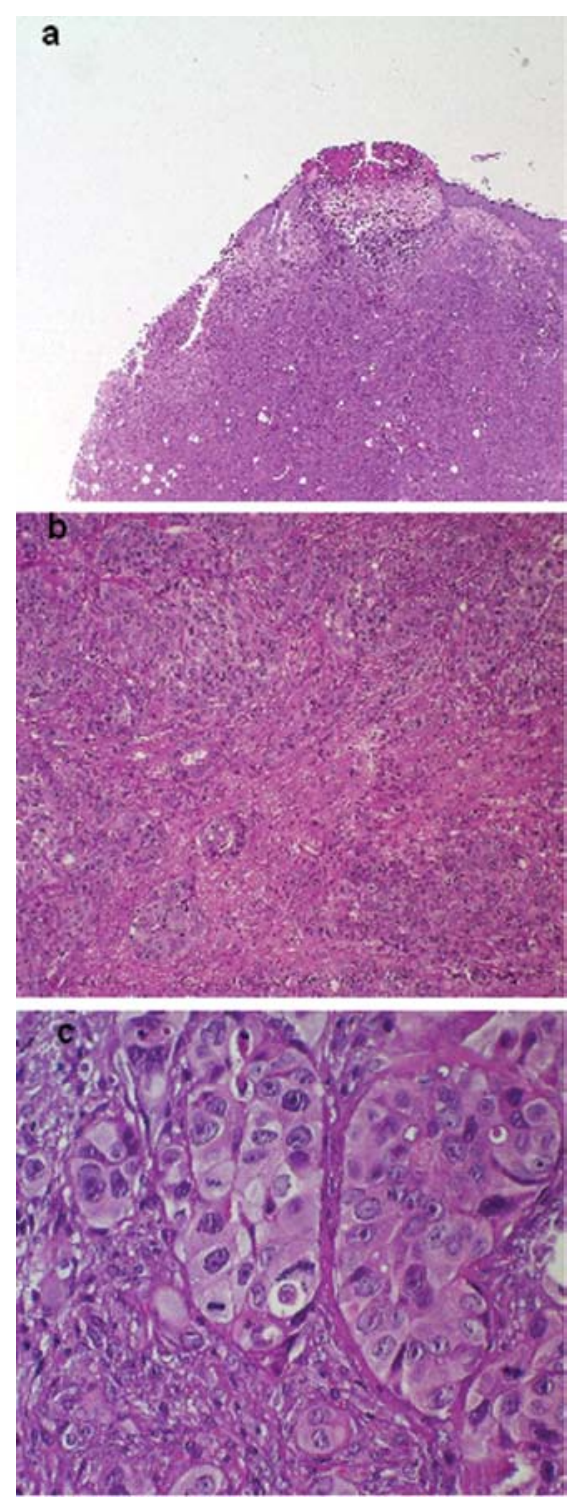

Figure 2. Histopathology. Histopathological examination by hematoxylin and eosin staining revealed no apparent differences in morphology of the tumors developed among all groups studied. Tumors tended to show central areas of necrosis. All developing tumors correspond to poorly differenciated adenocarcinomas. (A) Growthing diffuse tumor. (B) Same image at major augment. Growth diffuse tumor with tumor necrosis zones. (C) Augment image (x40), of the same tumor with non-typical nucleous.
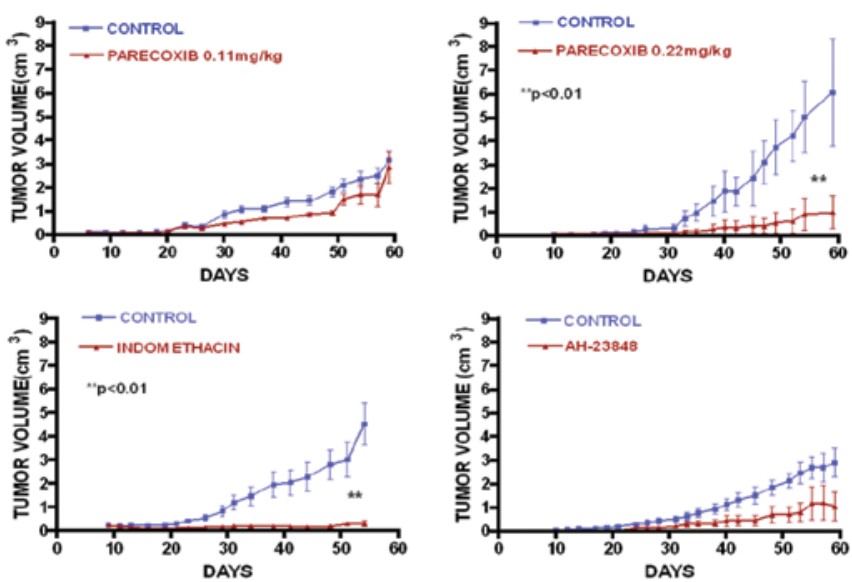

Figure 4. Effects of treatments on tumor volume. The agents were administered daily in drinking water for 8 weeks to female Swiss nu/nu mice bearing subcutaneous human OE33 esophageal adenocarcinoma cell-derived tumors. Control mice were administered with ethanol (solvent of agents) daily for 8 weeks. (A) Parecoxib (0.11 mg/kg body weight). (B) Parecoxib $(0.22 \mathrm{mg} / \mathrm{kg}$ body weight). (C) Indomethacin $(3 \mathrm{mg} / \mathrm{kg}$ body weight). (D) AH-23848B (1 mg/kg body weight). Tumor volume was determined with the use of calipers every 3 days. Data are shown as tumor volume each day during 60 days $(n=6$ mice per group, except for indomethacin, $\mathrm{n}=5$ ). Bars correspond to standard desviation. ${ }^{* *} \mathrm{p}<0.01$ for $0.22 \mathrm{mg} / \mathrm{kg}$ parecoxib vs control and $3 \mathrm{mg} / \mathrm{kg}$ indomethacin vs control (Kolmogorov-Smirnov with Lilliefors modification).

RNA extraction kit (Qiagen, Crawley, Surrey, UK) according to the manufacturer's protocol. RNA $(1.25 \mu \mathrm{g})$ was reverse transcribed using Superscript II (Invitrogen) in a total volume of $20 \mu 1$, and the resulting first-strand complementary DNA (cDNA) was used as a template for real-time quantitative polymerase chain reaction (PCR). Real-time PCR analysis was performed on cDNA (62.5 ng) generated by reverse transcription using an ABI PRISM 7000 Sequence Detection System and pre-developed TaqMan assay reagents (Applied Biosystems, Foster City, CA, USA): Hs00377721_m1 for COX-1 gene, Hs00153133_m1 for COX-2, HS00168752_m1 for $\mathrm{EP}_{1}$, HS00168754_m1 for $\mathrm{EP}_{2}$, HS00168755_m1 for $\mathrm{EP}_{3}$ and HS00168761_m1 for $\mathrm{EP}_{4}$. The PCR reactions were performed according to the manufacturer's protocol. The housekeeping TATA-box binding protein (human

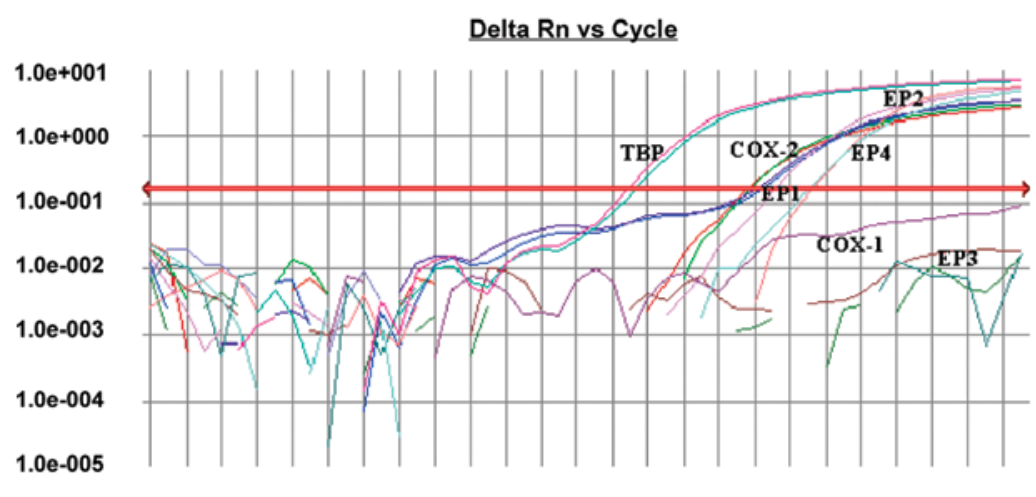

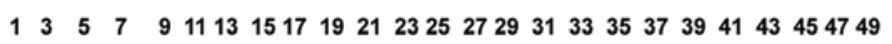

Figure 3. COX isozymes and EP receptor RNA expression. A representative amplification curve of the real-time PCR of cDNA retrotranscribed from RNA extracted from an $\mathrm{OE} 33$ tumor, showing amplification of $\mathrm{COX}-2, \mathrm{EP}_{1}, \mathrm{EP}_{2}$ and $\mathrm{EP}_{4}$ transcripts but no amplification of the cDNA when specific probes to $\mathrm{EP}_{3}$ receptor or COX-1 were used. 
Table I. Tumor parameters in treated and non-treated groups. ${ }^{\mathrm{a}}$

\begin{tabular}{lccrr}
\hline Group & $\mathrm{n}$ & $\begin{array}{c}\mathrm{V}_{\mathrm{T}} 60\left(\mathrm{~cm}^{3}\right) \\
\text { Mean } \pm \mathrm{SE}\end{array}$ & $\begin{array}{r}\text { Tumor inhibition } \\
(\mathrm{TI})\end{array}$ & $\begin{array}{r}\text { Tumor remission } \\
(\mathrm{Rt})\end{array}$ \\
\hline Control & & $3.19 \pm 0.34$ & 0 & $900 \%$ \\
Parecoxib 0.11 mg/kg & 6 & $2.87 \pm 0.68$ & $30.6 \%$ & $576.9 \%$ \\
Control & 6 & $6.07 \pm 0.92$ & 0 & $4719 \%$ \\
Parecoxib 0.22 mg/kg & 6 & $1.01 \pm 0.28$ & $82.6 \%$ & $823.3 \%$ \\
Control & 6 & $4.54 \pm 0.8$ & 0 & $58 \%$ \\
Indomethacin & 6 & $0.3 \pm 0.12$ & $62.8 \%$ & $74 \%$ \\
Control & 5 & $2.9 \pm 0.59$ & 0 & $3376 \%$ \\
AH-23848B & 6 & $1.04 \pm 0.6$ & $57 \%$ & $1118.6 \%$
\end{tabular}

${ }^{\text {aT }}$ Tumor volume was calculated from the start of treatment, expressed by the formula Vt/V0, were Vt is the volume on any given day and V0 is the volume on day 0 . The ratio of the mean relative volume of treated tumors over that of control tumors multiplied by $100 \%$ was assessed on each day of measurement. Tumor inhibition was expresses by the formula $(1-\mathrm{Vt} / \mathrm{Vc}) \times 100 \%$, and tumor remission by $(\mathrm{Vt} / \mathrm{Vi}) \times 100$.

TBP control reagent kit, Applied Biosystems) was also analysed as an endogenous constitutive gene.

Prostaglandin $E_{2}$ measurement in tumors. To confirm that COX-2 inhibitors influence prostaglandin synthesis in the tumor, $\mathrm{PGE}_{2}$ levels were assessed in tumors from mice which had received indomethacin or parecoxib and their respective control groups. For this purpose, a fragment of frozen tumor tissue was weighed and homogenized in $1 \mathrm{ml}$ PBS containing indomethacin $10 \mu \mathrm{M}$, centrifuged, and the supernatants collected. The extraction of prostanoids was performed by using C18 Sep-pak cartridges, according to the method previously described (37). After evaporation of the organic extracts to dryness under a stream of N2, the dry residues were dissolved in assay buffer $(0.05 \mathrm{M}$ Tris/ $\mathrm{HCl}$ pH 7.4 containing $0.9 \% \mathrm{NaCl}, 0.01 \%$ Triton X-100) and the concentrations of immunoreactive $\mathrm{PGE}_{2}$ were measured using radio-immunoassay (RIA) commercial kits purchased from Amersham.

Statistical analysis. Statistical analysis of the effects of treatments on tumor growth was carried out using a repeated measurements variance analysis with an inter-subject factor, which was the treatment applied (control/drug), and an intra-subject factor, which are the measurements at different times after tumor implantation. We have evaluated differences between the treatment group and the control group and differences in the evolution according to the treatment administered. In order to assess the evolution, the analysis was limited to five measurements, which were systematically chosen among the 22 measurements done. To test the normality we used the Kolmogorov-Smirnov with Lilliefors modification. Comparison of tumor $\mathrm{PGE}_{2}$ levels between treated and control mice were examined by a One-way non-parametric Kruskal-Wallis test. Statistical significance was defined as $\mathrm{p} \leq 0.05$. All $\mathrm{p}$-values are two-sided.

\section{Results}

Determination of the optimal cellular concentration and tumor growth. Several experiments were carried out in order to establish the optimal cellular concentration needed for tumor development. Different concentrations of OE33 cells were inoculated subcutaneously in several mice: $2.5 \times 10^{6}$ cells $(n=3)$, $5 \times 10^{6}$ cells $(n=3)$ and $10^{7}$ cells $(n=7)$. Among the amounts tested, the optimal number of cells to obtain tumors was $10^{7}$ cells. Thus, inoculation of $10^{7}$ cells which corresponded to subculture passage 14th, resulted tumorigenic in $75 \%$ of inoculated mice. However, none of mice inoculated with the same amount of cells in passage 27th developed tumors, indicating that cellular subculture affected the tumorigenic ability of this cell line. Developed tumors corresponded to poorly differentiated adenocarcinomas, as shown in Fig. 2.

EP receptors and COX expression $m R N A$ in OE33 xenografts. Real-time PCR showed that OE33 tumors expressed mRNAs for $\mathrm{COX}-2, \mathrm{EP}_{1}, \mathrm{EP}_{2}$ and $\mathrm{EP}_{4}$, but transcripts of $\mathrm{EP}_{3}$ receptors and COX-1 were undetectable (Fig. 3). Among the EP receptors, $\mathrm{EP}_{4}$ transcripts levels were the highest $(\mathrm{Ct}=29)$, where $\mathrm{Ct}$ is the threshold cycle, which indicates the cycle number at with the amount of amplified target reaches a fixed threshold, and it is inversely correlated to the amount of copies of the target gene in the sample.

Effect of indomethacin, parecoxib and AH23848 administration on tumor growth. As shown in Fig. 4, oral administration of parecoxib $(0.22 \mathrm{mg} / \mathrm{kg})$ and indomethacin $(3 \mathrm{mg} / \mathrm{kg})$ significantly decreased tumor growth of the xenografts compared with their corresponding control groups. In comparison to the control group, tumor volume was inhibited by $82.6 \%$ in the parecoxib $(0.22 \mathrm{mg} / \mathrm{kg})$ group, and by $62.8 \%$ in the indomethacin group. Furthermore, indomethacin induced tumor remission. Although the mean volume of the xenografts were smaller in the groups treated with parecoxib $(0.11 \mathrm{mg} / \mathrm{kg})$ or $\mathrm{AH}-23848 \mathrm{~B}(1 \mathrm{mg} / \mathrm{kg})$ than in the control groups receiving vehicle, these differences did not reach statistical significance (Table I). It is noteworthy that treatment with parecoxib at doses tested and with AH-23848B had no adverse effects on the health of experimental animals. One mouse receiving indomethacin suffered a duodenal perforation and was sacrificed before the end of the experiment. Due 
Table II. Determination of $\mathrm{PGE}_{2}$ concentrations in tumor tissue. ${ }^{\mathrm{a}}$

\begin{tabular}{lcc}
\hline Mouse groups & $\mathrm{PGE}_{2}$ per tissue (ng/g tissue) \\
\cline { 2 - 3 } & Mean & SEM \\
\hline Control & 58.1 & 10.5 \\
Parecoxib $0.11 \mathrm{mg} / \mathrm{kg}$ & 62.0 & 4.9 \\
Control & 65.5 & 9.5 \\
Parecoxib $0.22 \mathrm{mg} / \mathrm{kg}$ & 35.3 & 4.9 \\
Control & 34.7 & 3.4 \\
Indomethacin & 3.02 & 2.1 \\
\hline
\end{tabular}

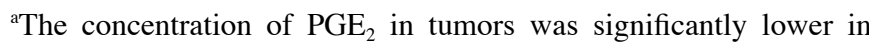
mice treated with parecoxib $0.22 \mathrm{mg} / \mathrm{kg}$ and indomethacin but not in animals treated with parecoxib $0.11 \mathrm{mg} / \mathrm{kg}$, than in their respective control groups.

to heterocedascity, a logarithmic transformation of data was performed for analysis of the effects. When we analysed the group treated with parecoxib at the lowest dose the differences were not significant when comparing control group to treated group ( $\mathrm{p}=0.162$ ), and non-significant evolution resulted among the two groups $(\mathrm{p}=0.227)$. In the group treated with parecoxib at the highest dose the differences were significant comparing control group to treated group ( $\mathrm{p}<0.01)$, and a significant evolution resulted among the two groups $(p<0.01)$. In the group treated with indomethacin the differences were significant comparing control group to treated group $(\mathrm{p}<0.01)$, and evolution among the two groups ( $\mathrm{p}=0.059)$. In the group treated with $\mathrm{AH}-23848 \mathrm{~B}$ the differences were not significant comparing control group to treated group $(\mathrm{p}=0.073)$, and non-significant evolution resulted between the two groups $(\mathrm{p}=0.304)$.

$P G E_{2}$ levels in tumors. The mean concentration of $\mathrm{PGE}_{2}$ in tumor tissue was $58.1 \pm 10.5 \mathrm{ng} / \mathrm{g}$ tissue, $65.5 \pm 9.5 \mathrm{ng} / \mathrm{g}$ and $34.7 \pm 3.4 \mathrm{ng} / \mathrm{g}$ for the 3 control groups, whereas it was $62.0 \pm 4.9,35.3 \pm 4.9$ and $3.02 \pm 2.1 \mathrm{ng} / \mathrm{g}$ for the parecoxib $(0.11 \mathrm{mg} / \mathrm{kg})$, parecoxib $(0.22 \mathrm{mg} /$ $\mathrm{kg}$ ), and indomethacin groups, respectively [results represent means \pm standard error (SE). PGE $_{2}$ levels of the tumors were significantly decreased in mice treated with parecoxib at the highest dose and indomethacin $(\mathrm{p}<0.05)$ compared with their respective control groups (vehicle-treated). However, tissue levels of $\mathrm{PGE}_{2}$ in the xenografts from mice treated with parecoxib at lower dose did not differ from the control group (Table II).

\section{Discussion}

Subcutaneous xenograft models in mice have been extensively used in tumorigenesis studies (38). The use of nude mice as recipients allows the study of the development and differentiation of the graft for long periods of time without immune rejection and is an excellent way for predicting drug response in human tumors (39-41). Depending upon the number of cells injected, or the size of the tumor xenograft transplanted subcutaneously, the tumor will develop over 4-8 weeks, and the response to appropriate therapeutic regimes can be studied in vivo. To date, very few studies have used this animal model to evaluate new thera- peutic alternatives for established esophageal adenocarcinoma. We have established an in vivo model of human esophageal adenocarcinoma in athymic mice starting from subcutaneous inoculation of OE33 cells. This cell line derives from a poorly differentiated adenocarcinoma of the lower esophagus of a patient who had Barrett's esophagus. These cells formed solid tumors resembling the histology of the original tumor from which the cell line was derived. Serial transplantation of OE33 xenografts did not modify either the histology or the amount of reactive estroma among tumor cells. Furthermore, OE33 xenografts grew more quickly than the primary tumors did, giving us the advantage to test the effects of the different treatments in a relatively short period. Obviously, results obtained in our study may not be extrapolated to other histological types of esophageal adenocarcinomas, and other cell lines derived from esophageal adenocarcinoma with different types of histology should be tested. In our model, the expression of COX isoenzymes and $\mathrm{PGE}_{2}$ receptors in the tumors developed in mice, showed similar pattern than OE33 cells in vitro, showing transcripts of COX-2, $\mathrm{EP}_{1}, \mathrm{EP}_{2}$ and $\mathrm{EP}_{4}$, but not COX-1 and $\mathrm{EP}_{3}$. Therefore, we believe that this model of OE33 xenografts in nude mice, is a useful tool to evaluate the effect of COX-2 inhibitors as well as antagonists of $\mathrm{EP}_{1}, \mathrm{EP}_{2}$ or $\mathrm{EP}_{4}$ receptors on the growth of established esophageal adenocarcinoma.

Targeting the prostaglandin pathway for the treatment of esophageal adenocarcinoma is solidly sustained by multiple lines of evidence: in vitro studies, epidemiological and clinical data. As a key rate-limiting control point of $\mathrm{PGE}_{2}$ biosynthesis, COX-2 continues to be an important anticancer target. Since COX-2 inhibitors are not void of adverse effects, especially at cardiovascular or renal level, their long-term use for cancer chemoprevention does not seem an acceptable therapeutic option. However, limitations due to toxicity are obviously different for their application on the treatment of esophageal adenocarcinoma, an extremely aggressive malignancy which causes a very poor quality of life and outcome to patients that suffer from it. In this study, we first tested parecoxib at a low dose $(0.11 \mathrm{mg} / \mathrm{kg} /$ day $)$. Since parecoxib is a newly developed drug for parenteral administration there are no studies on parecoxib orally. We decided to test this drug at very low doses to avoid any adverse effect, but we did not observe any effect with the lower dose tested. However, at a higher but still reasonable dose $(0.22 \mathrm{mg} / \mathrm{kg} / \mathrm{day})$, parecoxib significantly decreased tumor growth of OE33 xenografts compared to control mice. Other studies reporting anti-tumor effects of parecoxib have used even higher doses $(42,43)$. Thus, O'Donoghue et al, investigated the therapeutic efficacy of 15 daily intraperitoneal administrations of parecoxib $(0.5 \mathrm{mg} / \mathrm{kg})$ in mice bearing subcutaneous breast cancer xenografts and observed growth inhibition of the primary tumor and pulmonary metastases (44). Smakman et $a l$ studied the efficacy of twice-daily intraperitoneal injections of parecoxib $(5 \mathrm{mg} / \mathrm{kg})$ for 6 days in mice immediately after inducing liver metastases of colon carcinoma, and reported greatly reduced intrahepatic tumor cell proliferation and the rate of liver metastases outgrowth (45). Another study showed that daily intraperitoneal injections of high dose parecoxib (25 $\mathrm{mg} / \mathrm{kg}$ ) during 14 consecutive days inhibited tumor growth in four out of eight mice with peritoneal carcinomatosis of colonic origin (42). The doses of parecoxib used in the present study are, by far, lower than the maximum dose recommended in 
clinical practice, even in elderly patients or patients with liver insufficiency, to whom half of the habitual dose is recommended. In this study, mice receiving parecoxib did not show any detectable adverse effect. Therefore, the use of parecoxib at this dose may be perfectly assumed in the chemotherapeutic setting to decrease the aggressiveness of esophageal adenocarcinoma. We also tested the effect of indomethacin, a classic NSAID which had already shown to have anti-tumor effects in other type of neoplasias. In our model, administration of $3 \mathrm{mg} / \mathrm{kg} /$ day indomethacin not only significantly decreased the growth of OE33 xenografts but also induced tumor regression. This dose was in the normal therapeutic range since the normal adult human dose for indomethacin is $1-3 \mathrm{mg} / \mathrm{kg} / \mathrm{day}$, which is administered for the treatment of several rheumatic diseases, which suggests that this drug could be of therapeutic benefit in patients with established adenocarcinoma of the esophagus. However, NSAIDs induce gastrointestinal toxicity and in fact one animal suffered a duodenal perforation. Thus, the possibility to provide gastrointestinal protection with proton pump inhibitors may overcome, at least in part, this side effect.

It has been long assumed that the anti-tumor effects of NSAIDs are dependent on inhibition of COX activity and prostaglandin synthesis. This could be the mechanism explaining why indomethacin exerted a stronger antitumor effect than parecoxib at a dose of $0.22 \mathrm{mg} / \mathrm{kg} /$ day and why parecoxib at the lowest dose used had no effect in the present study. When we analysed $\mathrm{PGE}_{2}$ levels in tumor tissue, we found a profound and significant inhibition in indomethacin-treated mice when compared to tumors from non-treated mice. $\mathrm{PGE}_{2}$ levels were significantly inhibited in tumor extracts from mice treated with parecoxib $0.22 \mathrm{mg} / \mathrm{kg} / \mathrm{day}$, although to a lesser extent than indomethacin, whereas treatment with parecoxib at the lowest dose tested did not alter tumor $\mathrm{PGE}_{2}$ levels. These data suggest that COX-2 is in effect involved in the growth of this type of tumor. The stronger effect of indomethacin both on tumor growth and inhibition of $\mathrm{PGE}_{2}$ levels cannot be explained by its condition of dual COX-1/COX-2 inhibitor since OE33 tumors did not express COX-1. Although in the present study we have focused on the COX pathway, we cannot exclude the possibility that COX-independent mechanisms may contribute to the observed reduction in tumor growth. COX-independent effects have been reported for several non-steroidal anti-inflammatory drugs, such as sulindac, celecoxib, NS-398, or indomethacin $(46,47)$. Regarding indomethacin, in addition to COX-1 and COX-2, several studies have shown that it acts through different cellular targets involved on proliferation and apoptotic cellular events, such as PKD-1, PPAR, LOX, Bcl-XL, NAG-1 and Bax, which activates different pathways (NF- $\mathrm{B}, \mathrm{MAPK}, \mathrm{PPAR} \gamma$ or LOX) (48). Therefore, despite of $\mathrm{PGE}_{2}$ levels inhibition could be sufficient to explain the antineoplasic effect of indomethacin, any of these alternative mechanisms cannot be discarded. The effects seen with parecoxib could also be linked to $\mathrm{PGE}_{2}$ inhibition, but other COX-independent effects could not be excluded.

The blockage of $\mathrm{PGE}_{2}$ receptors as a chemotherapeutic target has not been evaluated in esophageal adenocarcinoma, although it has been effectively evaluated in several types of in vivo tumors. In the esophagus, Jiménez et al (11) showed that, in addition to $\mathrm{COX}-2, \mathrm{EP}_{2}$ and $\mathrm{EP}_{4}$ receptor expression and protein were increased in the Barrett's metaplasia-intraepithelial neoplasiaadenocarcinoma sequence. Among these two $\mathrm{PGE}_{2}$ receptors,
$\mathrm{OE} 33$ xenografts showed higher expression for $\mathrm{EP}_{4}$. This fact and the absence of an available selective antagonist for $\mathrm{EP}_{2}$ receptor, was the reason to evaluate an $\mathrm{EP}_{4}$ antagonist, in addition to $\mathrm{COX}$ inhibitors, in this model. Although tumor volume reached in the group of mice receiving AH-23848 was lower than in the control group, these differences were not statistically significant. The lack of significant effect may be due to an insufficient dose used to block $\mathrm{EP}_{4}$ receptor in tumor cells. Another possibility is that it may be necessary the simultaneous blockage of other receptors to inhibit completely the effects of $\mathrm{PGE}_{2}$ at tumor level. In the future, if a selective $\mathrm{EP}_{2}$ antagonist is developed, it should be tested for antitumor activity in esophageal adenocarcinoma, since this receptor is overexpressed in the carcinogenic sequence toward esophageal adenocarcinoma.

Another potential approach could be to combine drugs targeting COX pathway to drugs targeting other signalling pathways involved in the growth of esophageal adenocarcinoma such as epidermal growth factor, or vascular endothelial growth factor pathways for example. In effect, a combination therapy is a common strategy in the treatment of cancer. A low-dose combination of drugs could be more effective than each drug separately, and produces less toxicity. This concept has been supported by recent findings as have shown Torrance et al (49), who observed that the combination of an NSAID with an EGFR kinase inhibitor was more effective in reducing intestinal tumors developed in experimental models than each drug separately.

In conclusion, the experimental model of xenografts derived from OE33 cells established in nude mice may be a useful tool to investigate the mechanisms associated to the progression of esophageal adenocarcinoma, as well as to evaluate new therapeutic targets on COX-2 pathway. Our study offers evidence that both selective and non-selective COX-2 inhibitors at reasonable doses suppress the growth of human esophageal adenocarcinoma xenografts in athymic mice, suggesting a potential role for NSAIDs or coxibs in neoadjuvant treatment of esophageal adenocarcinoma. Therefore, clinical trials to determine the potential usefulness of COX inhibitors, alone or in combination with other drugs, are necessary.

\section{Acknowledgements}

We thank Sara Serrano from the Service of Pathology for her invaluable technical assistance. This study was supported with grants FIS (PI05/2445 and PI08/1047) and project B01 (Department of Science, Technology and University of Aragon Government).

\section{References}

1. Brown LM, Devesa SS and Chow WH: Incidence of adenocarcinoma of the esophagus among white Americans by sex, stage, and age. J Natl Cancer Inst 100: 1184-1187, 2008.

2. Botterweck AA, Schouten LJ, Volovics A, et al: Trends in incidence of adenocarcinoma of the oesophagus and gastric cardia in ten European countries. Int J Epidemiol 29: 945-954, 2000.

3. Parkin DM, Bray F, Ferlay J and Pisani P: Global cancer statistics. Cancer J Clin 55: 74-108, 2005.

4. Vaughan TL, Dong LM, Blount PL, et al: Non-steroidal antiinflammatory drugs and risk of neoplastic progression in Barrett's oesophagus: a prospective study. Lancet Oncol 6: 945-952, 2005.

5. Corley DA, Kerlikowske K, Verma R and Buffler P: Protective association of aspirin/NSAIDs and esophageal cancer: a systematic review and meta-analysis. Gastroenterology 124: 47-56, 2003. 
6. Piazuelo E, Jimenez P and Lanas A: COX-2 inhibition in esophagitis, Barrett's esophagus and esophageal cancer. Curr Pharm Des 9: 2267-2280, 2003.

7. LiZ,Shimada Y,KawabeA, et al: Suppression of N-nitrosomethylbenzylamine (NMBA)-induced esophageal tumorigenesis in F344 rats by JTE-522, a selective COX-2 inhibitor. Carcinogenesis 22: 547-551, 2001

8. Buttar NS, Wang KK, Leontovich O, et al: Chemoprevention of esophageal adenocarcinoma by COX-2 inhibitors in an animal model of Barrett's esophagus. Gastroenterology 122: 1101-1112, 2002.

9. Miwa K, Sahara H, Segawa M, et al: Reflux of duodenal or gastroduodenal contents induces esophageal carcinomas in rats. Int J Cancer 67: 269-274, 1996.

10. Oyama K, Fujimura T, Ninomiya I, et al: A COX-2 inhibitor prevents the esophageal inflammation-metaplasia-adenocarcinoma sequence in rats. Carcinogenesis 26: 565-570, 2005.

11. Jiménez P, Piazuelo E, Cebrian C, et al: Prostaglandin EP2 receptor expression is increased in Barrett's oesophagus and oesophageal adenocarcinoma. Aliment Pharmacol Ther 31: 440-451, 2010

12. Jacobson GA, Narkowicz C, Lord R, Howard BJ and Chung S: Effect of celecoxib on cyclooxygenase-2 expression and possible variants in a patient with Barrett's esophagus. Dis Esophagus 20: 265-268, 2007.

13. Li Y, Wo JM, Ray MB, et al: Cyclooxygenase-2 and epithelial growth factor receptor up-regulation during progression of Barrett's esophagus to adenocarcinoma. World J Gastroenterol 12: 928-934, 2006.

14. Kuramochi H, Vallbohmer D, Uchida K, et al: Quantitative, tissue-specific analysis of cyclooxygenase gene expression in the pathogenesis of Barrett's adenocarcinoma. J Gastrointest Surg 8: 1007-1016, 2004.

15. Morris CD, Armstrong GR, Bigley G, et al: Cyclooxygenase-2 expression in the Barrett's metaplasia-dysplasia-adenocarcinoma sequence. Am J Gastroenterol 96: 990-996, 2001.

16. Zimmermann KC, Sarbia M, Weber AA, et al: Cyclooxygenase-2 expression in human esophageal carcinoma. Cancer Res 59: 198-204, 1999.

17. Wilson KT, Fu S, Ramanujam KS and Meltzer SJ: Increased expression of inducible nitric oxide synthase and cyclooxygenase-2 in Barrett's esophagus and associated adenocarcinomas. Cancer Res 58: 2929-2934, 1998.

18. Buskens CJ, Van Rees BP, Sivula A, et al: Prognostic significance of elevate cyclooxygenase-2 expression in patients with adenocarcinoma of the esophagus. Gastroenterology 122: 1800-1807, 2002.

19. Breyer RM, Emeson RB, Breyer MD, et al: Alternative splicing generates multiple isoforms of a rabbit prostaglandin $\mathrm{E}_{2}$ receptor. J Biol Chem 269: 6163-6169, 1994.

20. Narumiya S, Sugimoto Y and Ushikubi F: Prostanoid receptors: structures, properties and functions. Physiol Rev 79: 1193-1226, 1999.

21. Båtshake B, Nilsson C and Sundelin J: Molecular characterization of the mouse prostanoid EP1 receptor gene. Eur J Biochem 231: 809-814, 1995.

22. Abramovitz M,Adam M,Boie Y, et al: Human prostanoid receptors: cloning and characterization. Prostaglandin Thromboxane Leukot Res 23: 499-504, 1995

23. Regan JW: EP2 and EP4 prostanoid receptor signaling. Life Sci 74: 143-153, 2003

24. Hull MA, Ko SC and Hawcroft G: Prostaglandin EP receptors: targets for treatment and prevention of colorectal cancer? Mol Cancer Ther 3: 1031-1039, 2004.

25. Bastien L, Sawyer N, Grygorczyk R, Metters KM and Adam M: Cloning, functional expression, and characterization of the human prostaglandin E2 receptor EP2 subtype. J Biol Chem 269 11873-11877, 1994.

26. George RJ, Sturmoski MA, Anant S and Houchen CW: EP4 mediates PGE2 dependent cell survival through the PI3 kinase/ AKT pathway. Prostaglandins Other Lipid Mediat 83: 112-120, 2007.

27. Watanabe K, Kawamori T, Nakatsugi S, et al: Inhibitory effect of a prostaglandin E receptor subtype $\mathrm{EP}(1)$ selective antagonist, ONO-8713, on development of azoxymethane-induced aberrant crypt foci in mice. Cancer Lett 156: 57-61, 2000.
28. Sonoshita M, Takaku K, Sasaki N, et al: Acceleration of intestinal polyposis through prostaglandin receptor EP2 in Apc(Delta 716) knockout mice. Nat Med 7: 1048-1051, 2001.

29. Niho N, Mutoh M, Kitamura T, et al: Suppression of azoxymethane-induced colon cancer development in rats by a prostaglandin E receptor EP1-selective antagonist. Cancer Sci 96: 260-264, 2005.

30. Piazuelo E, Jiménez P, Strunk M, Santander S, et al: Effects of selective PGE2 receptor antagonists in esophageal adenocarcinoma cells derived from Barrett's esophagus. Prostaglandins Other Lipid Mediat 81: 150-161, 2006.

31. Tuynman JB, Buskens CJ, Kemper K, et al: Neoadjuvant selective COX-2 inhibition down-regulates important oncogenic pathways in patients with esophageal adenocarcinoma. Ann Surg 242: $840-849,2005$

32. Sawaoka H, Kawano S, Tsuji S, et al: Cyclooxygenase-2 inhibitors suppress the growth of gastric cancer xenografts via induction of apoptosis in nude mice. Am J Physiol 274: G1061-G1067, 1998.

33. Britain RT, Boutal L, Carter MC, et al: AH23848: a thromboxane receptor-blocking drug that can clarify the pathophysiologic role of thromboxane A2. Circulation 72: 1208-1218, 1985.

34. Rockett JC, Larkin K, Darnton SJ, Morris AG and Matthews HR: Five newly established oesophageal carcinoma cell lines: phenotypic and immunological characterization. Br J Cancer 75: 258-263, 1997.

35. Van Hattum AH, Pinedo HM, Schluper HM, Hausheer SH and Boven E: New highly lipophilic camptothecin BNP 1350 is an effective drug in experimental human cancer. Int J Cancer 88: 260-266, 2000

36. Jansen WJ, Kolfschoten GM, Erkelens CA, van Ark-Otte J, Pinedo HM and Boven E: Anti-tumor activity of CPT-11 in experimental human ovarian cancer and human soft-tissue sarcoma. Int J Cancer 73: 891-896, 1997.

37. Powell WS: Reversed-phase high-pressure liquid chromatography of araquidonic acid metabolites formed by cyclooxygenase and lipoxygenase. Anal Biochem 154: 332-337, 1986.

38. Morton CL and Houghton PJ: Establishment of human tumor xenografts in immunodeficient mice. Nat Protoc 2: 247-250, 2007.

39. Fidler IJ: New developments in in vivo models of neoplasia. Cancer Metastasis Rev 10: 191-192, 1991.

40. Eccles SA, Box G, Court W, Sandle J and Dean CJ: Preclinical models for the evaluation of targeted therapies of metastatic disease. Cell Biophys 24-25: 279-291, 1994.

41. Hoffman RM: Orthotopic is orthodox: why are orthotopictransplant metastatic models different from all other models? J Cell Biochem 56: 1-3, 1994

42. Padi SS, Jain NK, Singh S and Kulkarni SK: Pharmacological profile of parecoxib: a novel, potent injectable selective cyclooxygenase-2 inhibitor. Eur J Pharmacol 491: 69-76, 2004

43. Talley JJ, Bertenshaw SR, Brown DL, et al: N-[[(5-methyl-3phenylisoxazol-4-yl) phenyl]sulfonyl]propanamide, sodium salt, parecoxib sodium: a potent and selective inhibitor of COX-2 for parenteral administration. J Med Chem 43: 1661-1663, 2000.

44. O'Donghue GT, Roche-Nagel G,Harmey JH and Bouchier-Hayes DJ: Cyclooxygenase-2 inhibition attenuates surgically induced residual tumor growth and metastases following cytoreductive surgery in a murine model of breast cancer. J Surg Res 114: 227, 2003.

45. Smakman N, Kranenburg O, Vogten JM, Bloemendaal AL, van Diest P and Borel Rinkes IH: Cyclooxygenase-2 is a target of KRASD12, which facilitates the outgrowth of murine C26 colorectal liver metastases. Clin Cancer Res 11: 41-48, 2005.

46. Klein WA, Miller HH, Anderson M and De Cosse JJ: The use of indomethacin, sulindac, and tamoxifen for the treatment of desmoid tumors associated with familial polyposis. Cancer 60 : 2863-2868, 1987.

47. Zhang X, Morham SG, Langenbach R and Young DA: Malignant transformation and antineoplastic actions of non-steroidal antiinflammatory drugs (NSAIDs) on cyclooxygenase-null embryo fibroblasts. J Exp Med 190: 451-459, 1999.

48. Chiu CH, McEntee MF and Whelan J: Sulindac causes rapid regression of preexisting tumors in Min/+ mice independent of prostaglandin biosynthesis. Cancer Res 57: 4267-4273, 1997.

49. Torrance CJ, Jackson PE, Montgomery E, et al: Combinatorial chemoprevention of intestinal neoplasia. Nat Med 6: 1024-1028, 2000 . 